\title{
Women's Biological Threat to Confucian Social Order: An Examination of Gender Constructs through an Analysis of Pre- Modern Chinese Literature
}

\author{
Megan Pellouchoud*, Asian Studies
}

\begin{abstract}
Cultural views embedded within an array of pre-modern Chinese literature unveil social and gender constructs designed to promote Confucian social order. Confucian culture prioritizes the reproduction of sons, in order to maintain ancestor worship and social order, whereas literature from this period does not celebrate the female's biological role in reproduction. Instead, women's biological role in reproduction is characterized as unfavorable and disrupting to social order, while the social role of motherhood is idealized and represented as stabilizing to social order. Consequently, the biological processes associated with female reproduction are ranked on a hierarchical scale reflecting women's social position that conforms with Confucian gender hierarchies and social mores. An interpretation and analysis of traditional Chinese literature reveals that the positive aspects associated with the social role of motherhood override the negative aspects associated with the biological role. Within this construct, the biological role of motherhood was restrained by depictions of pollution and represented as inferior to the social role. Furthermore, female reproductive power was framed as secondary to men. These societal views parallel Confucian social and gender hierarchies that promote the female role of biological reproduction as a threat to social order.
\end{abstract}

Even though Confucian culture prioritizes the reproduction of sons to maintain ancestral worship, many pre-modern Chinese texts depict the female biological role in reproduction as inferior to the male role and destabilizing to social order. The female role in reproduction is represented by the biological and social attitudes surrounding motherhood in Confucian culture, demonstrated by divisions in maternal roles.

\footnotetext{
* Megan Pellouchoud is a senior at the University of Oregon with a completed degree in Asian Studies and a minor in Korean. Although the majority of Megan's research pertains to the historical and political processes underlying the Korean peninsula and Korean Linguistics, her interests transcend to several disciplines, including Chinese literature and society, in which she garnered motivation to research this topic in the beginning of her junior year. After graduation, Megan has ambitions to attend graduate school after completing further language training in South Korea. In graduate school, she would like to extend her focus to Chinese politics and language. During work, she is an avid coffee drinker. During leisure time, she enjoys moderate exercise, reading Korean comics, and consuming horror and gore films. Please send correspondence to mpellouc@uoregon.edu.
} 
Furthermore, substances associated with female biological reproductive processes are consistently depicted as polluting and harmful to social order. An analysis of societal views surrounding female reproduction and divisions of maternal roles reveals the pervasive moral authority of Confucian social and gender hierarchies in pre-modern China. The moral authority of Confucian values informs the social position of women, which is imitated by and reinforced through the cultural perception of male and female reproductive processes. Among an array of pre-modern Chinese texts compiled from different periods, not one passage, including those written by women, celebrated the female role in reproduction.

\section{DIVISIONS IN MATERNAL ROLES: BIOLOGICAL VS. PROPER SOCIAL MOTHERHOOD}

When examining women's role in reproduction within pre-modern China, the article "Reproductive Hierarchies" discusses the biological and social functions of motherhood in relation to social status. The article acknowledges that pre-modern China permitted a range of reproductive freedom and privilege; however, reproductive decisions were dependent on the interests of the kin group and determined by a woman's contribution to the patriline (Bray 340). This is supported in the Book of Rites, a foundational Confucian educational text that outlines etiquette appropriate to maintain social order. The section titled "The Pattern of the Family," in the Book of Rites, states that "the purpose of marriage was to produce heirs for the lineage and continue the ancestral cult" (358). Thus, the biological role of motherhood signifies the obligation to fulfill the ritual duties of creating a multi-generational family. Despite this reproductive purpose assigned to women, the biological role of motherhood is described as coming "at the price of depletion, pollution, pain, sickness, and sin" (343). This characterization of the biological role of motherhood links the biological processes of women during reproduction to pollution and sin. Confucian culture balances this unfavorable view of women's biological role in reproduction by idealizing the social role of motherhood. The social ideals of motherhood are structured within class differences, which differentiate the motherly tasks between elite and non-elite women. The article reinforces the social ideal which holds that an elite mother's most important contribution was the moral education of a child. The emphasis on elite mothers' social roles suggests that a "woman's greatness was based on how well they raise children [through intellectual cultivation]," rather than their biological capability to nurture a child (347). While elite women were assigned the maternal responsibility for the moral upbringing of a child, non-elite women in the household were assigned the negatively-viewed burdens, including the material tasks of motherhood. This is further reflected by the elite ideal of feminine beauty in late-imperial China. Beauty was defined by a slender physical frame expressing the refinement and moral purity desirable for an elite mother. However, nonelite women, such as maids and concubines, are described as robust and naturally fertile, well-designed for easily giving birth (350). These divisions in maternal responsibility suggest that "proper motherhood" is represented "not by giving birth, not 
by suckling or changing diapers, but by giving the child a proper moral upbringing" (349). The social role of motherhood is thereby respected and idealized, while the biological role of motherhood is subordinated and made to be unfavorable. Overall, the article suggests that a woman's biological role in reproduction is tainted with negativity and disdain, which is reflected in the division of maternal roles within women's social hierarchies. This conversely promotes the social role of motherhood and frames the biological role with less respect and admiration. The division of reproductive and maternal roles between non-elite and elite women corroborates this social hierarchy.

Selections from Exemplary Women of Early China, with texts from as early as 79 BCE, survey attitudes about women's social and biological role in reproduction. This text demonstrates the trend of negativity surrounding female reproduction, while outlining Confucian gender ideals for women. One such selection involves a mother, Jiang Yuan, who conceives a child in an unnatural, inauspicious way. Yuan's pregnancy is regarded as "unnatural and loathsome" and therefore burdensome (Liu 3). Yuan chooses to abandon the child in a narrow lane; however, supernatural occurrences prevent the child from being harmed, motivating Yuan to keep her child. It is interesting how Yuan's choice to abandon and sacrifice her son is tolerable and sanctioned because of the unnatural circumstances of the pregnancy. However, her initial choice to abandon the child is viewed as acceptable because it contributes to protecting the community and preserving social order. However, when Heaven intervenes and protects the child, Jiang Yuan recognizes the child's potential. When the son grows older, he ascends to minister of agriculture after learning skills from his mother and moves on to establish the kingdom. In conclusion, Heaven reveres Jiang Yuan's role as a social mother who raised her son to excel and rewards her with a multitude of food (4). From this selection, it is apparent that the inauspicious conception associated with her pregnancy contributed to both her desire to sacrifice the pregnancy and her choice to abandon the child. However, Heaven's intervention reverses her decision and Jiang Yuan's role as a social mother to her son characterizes her as virtuous. An additional selection from this collection emphasizes this role of social mother through Jiandi, mother of Xie. Although Jiandi mistakenly gives birth to Xie, she validates her decency by teaching Xie moral principles and being mindful to Confucian ritual. Jiandi and "her capacity to instruct" is respected, underscoring her role as a social mother (5). These selections further demonstrate how a mother's social role is idealized and overrides a mother's negative biological role in premodern Chinese texts.

Although Confucian culture prioritizes a woman's biological role as a method to reproduce heirs for the lineage, the biological processes associated with childbirth are treated as polluting and harmful. "The Power and Pollution of Chinese Women," reveals how the most polluting or damaging substances were those associated with reproductive processes of women, such as menstrual blood and birth fluids. Although men were considered to contribute to and produce polluting substances, their role is less immediate than that of women due to biology. By default, women share proximity to 
uncleanliness due to their direct affiliation with birth. The hierarchy of impure substances places women's reproductive processes at the top. Thus, biological processes are biased and labeled through a lens compatible with social constructs of gender in Chinese society, and such constructs were designed to promote Confucian social order. The double standard on how substances are ranked on a hierarchal scale of pollution is demonstrated in various ways. The article recognizes that urine, feces, and pus are undeniably dirty; however, substances such as menstrual blood and birth fluids receive a more severe ranking in terms of what is unclean. Substances, such as menstrual blood, "cannot be alleviated by soap and water" and require a ritual process of extensive cleansing (Ahern 172). Menstrual blood is recognized as the "flesh and bones" of a child, and semen is assigned the equally critical ability to start the growth of a child. Yet menstrual blood is considered to be more harmful and polluting than male substances such as semen. The assigned labels of dirtiness are also associated with deities of birth, where "little low goddesses" are considered less clean and ranked lower than other gods because of their associations with childbirth (182). This implies that events like childbirth are attached with notions of negativity, regardless of the occasion being considered as a happy event, since childbirth threatens the stability and integrity of the family (188). Consequently, events like childbirth are framed with anxiety and negativity because of the potential disruption to the order and stability of the family. The dirtiness of women's bodily substances is directly linked to their bodies, as when the womb is described as a "vessel of contamination" (179). A woman's physicality is thus linked to intrinsic dirtiness, while no such associations existed for a man. Furthermore, the double standard is replicated in the treatment of male and female offspring. Male offspring fit within the social hierarchies and are considered less dirty, while female offspring require a more extensive cleansing process after birth (185). This double standard echoes the hierarchies of polluting substances and gender, which were constructed in relation to paternity. In an investigation of perceptions of the human body and polluting substances, "substances that cross bodily boundaries were considered to be unclean," such as pus from sores, which may be "indicative of disorder within the body, such as an imbalance or excess of poison" (184). If one expands this concept to birthing processes, birth is considered more polluting because "birth entails the crossing both bodily and familial boundaries. Blood flows from the mother's body, and the family must be redefined to include the new member" (185). When gender constructs are introduced, bodily substances are ranked on a hierarchal scale that imitate gender hierarchy within Confucian society. This gender hierarchy upholds negative impressions of childbirth and other female reproductive processes, where bodily substances are interpreted and perceived as polluting and destructive.

\section{CASES OF FEMALE'S ROLE IN REPRODUCTION AS POLLUTING AND SECONDARY TO MEN}

Notions of internal pollution and negativity surrounding birthing processes are represented in Pu Songling's "The Painted Skin," from the seventeenth century, which 
emboldens anxieties surrounding women and their polluting qualities. The story involves a Confucian scholar, named Wang, who takes a leisurely walk and encounters a lone, beautiful woman, and then offers his home to her ( $\mathrm{Pu}$ 53). After growing suspicious of the girl, he looks through his studio window to discover a "frightful demon with a green face and jagged saw-like teeth" spreading its human skin onto the bed to paint it to appear as a young woman (55). This depiction conveys implicit attitudes about a woman's beautiful exterior and their polluting interior and is intended to discourage men from acting on their desires. The depiction of the internal form of the woman as a demon resonates with the system of ideas which describe a woman's body as a polluting, sinful vessel. The demon's painted skin reflects male social anxiety for women to manipulate their exterior to create the illusion of decency. Additionally, the representation of the woman's exterior as a beautiful young maiden who claims to be an ill-treated concubine upholds the social class divide between elite and non-elite women. The concubine's beauty is external, and her fertile qualities and affinity with birth are the predominant, polluting forces. When the demon rips out Wang's heart, the wife of the household, Chen, assumes her obligation to remain loyal. Chen seeks out a madman to help restore her husband's life. The madman instructs her to ingest his phlegm. When it comes time to bury her husband's corpse, Chen expels the phlegm of the madman into her husband's chest cavity, and the substance forms a beating heart (59). This sequence of events is a metaphor for birth, as Chen's husband has been reborn from the phlegm of the madman. This representation of birth reflects the hierarchy of polluting substances, where substances from a man are interpreted as less polluting and sometimes as purifying compared to the substances a woman releases in childbirth. The phlegm originating from the madman is the substance that restores the husband's heartbeat. However, the rebirth is fertile only because Chen is absent of desire and wants to remain loyal by helping her husband. Pu Songling's choice to represent the rebirth of the husband through the madman's phlegm, rather than Chen's reproductive capacity, reflects the polluting hierarchy that aligns with Confucian gender hierarchy. Chen's biological role in this rebirth is omitted and treated as insignificant. Yet, the combination of phlegm from the madman and optimum social qualities from an elite wife, represented by Chen's fidelity to her husband, provides the balance required to revive her husband and restore order. The overall story implies that a woman's innate uncleanliness is linked to her reproductive processes, which promotes the attitude surrounding the inferiority of a woman's biological role in reproduction, compared to the role of men.

The "Biography of the Great Compassionate One of Xiangshan," from the eleventh century common era, contains Buddhist perspectives that give women an opportunity to challenge the Confucian gender paradigm and achieve a level of self-determination. However, this Buddhist rendering of the Miaoshan legend still appropriates key Confucian themes about reproduction, which project the power of reproduction onto men. In the beginning of the story, Miaoshan challenges her father's desire that she marry in order to practice the Way and attain enlightenment ( $\mathrm{Yu}$ 34). The father 
disagrees and exiles Miaoshan. When the father becomes ill, a monk informs that the only remedy is the "arms and eyes" of one without anger (40). An envoy seeks such an individual, who is dressed like a hermit in Xiangshan, and the hermit sacrifices her eyes and arms to heal the King. When the king goes to seek out the hermit in Xiangshan, to express gratitude for his recovery, he discovers the hermit is his daughter. In an act of filial piety, "[Miaoshan] offered up her hands and arms to repay her father's love" (41). To restore Miaoshan's eyes and arms, the father must "lick my child's two eyes with my tongue and rejoin her arms" (42). Miaoshan's father's desire to restore her limbs is viable due to the reproductive power underlying the father's tongue, to make his "child's withered eyes grow again" (42). This depiction is another symbolic rendering of birth, which is intended to highlight the reproductive capacity of a male through the phallic imagery of the father's tongue. The symbolic imagery of the father's tongue is interpreted as phallic because it resembles the reproductive power structure in birthing processes between males and females in pre-modern China that reinforce Confucian gender hierarchy. Miaoshan, due to her father, grows a thousand eyes and a thousand arms appearing "solemn and majestic in form, radiant with dazzling light, lofty and magnificent, like the moon among stars" (42). The pure and successful rendition of Miaoshan's rebirth bears no resemblance to attitudes toward childbirth accomplished by women. Actual childbirth by women is consistently depicted as undesired, contaminating, and inferior. As a result of the immaculate rebirth of Miaoshan and the power of male sexuality, she becomes a bodhisattva and achieves enlightenment.

The fictional text by Li Yu, "A Male Mencius's Mother Raises her Son Properly by Moving House Three Times," continues to convey this attitude of women's biological role in reproduction as secondary and negative. The story begins by describing a young man named Xu Wei, also known as Xu Jifang, who prefers the company of men due to women possessing "several objectionable features." These objectionable features include the polluting process and negative consequences of childbirth. For example, after giving birth, women are "as vast as the sea" and women "stain their bed mat and clothes during menstruation" (Li 103). When Jifang meets Ruilang, a "matchless beauty" compared to himself, he desires him as his companion. The story inverts Confucian female gender ideals and applies them to Ruilang; for example, when Ruilang's father requires $\mathrm{Xu}$ Jifang to pay a dowry prior to taking in Ruilang as his partner, which would be typical in arranged marriages by males to females (111). Also, Ruilang embodies all the social and physical ideals of a female as he assumes the social role of a woman. Ruinang is described as cloistered, being chaste and loyal to Jifang, and having bound feet, which are all ideal qualities for an elite female. Ruilang's fidelity to Jifang is demonstrated when he castrates himself to show his appreciation and loyalty to Jifang (120). In Ruilang's recovery, his wound is described as closing in less than a month and resulting in a scar "resembling a vagina" (121). Without his male organ, Ruilang is depicted as undistinguishable from female. This also implies; however, that Ruilang, now Ruinang, has no threat of internal pollution due to his initial existence as a male. Thus, Ruinang represents all the ideals of a social female without the associated pollution, making him 
the perfect partner. Although Ruinang cannot reproduce children of his/her own, Ruinang's role as a social mother to Jifang's son, Chengxian, is emphasized and overrides her biological role of reproduction. Ruinang's role as a social mother is represented as impeccable, as she is devoted to her son's moral upbringing and motivates him to study and pass examinations. Thus, Ruinang represents a subversion of Confucian gender roles by assuming exclusively the ideal qualities and roles of a woman. However, Ruinang is still depicted as aligning to Confucian orthodoxy because Ruinang adequately fulfills the roles of a social woman, perhaps to an even greater extent than can be upheld by a biological female. Consequently, the emphasis on Ruinang's social role as a mother deemphasizes the biological role of women in reproduction.

An additional fictional text, "Liansuo" from seventeenth century China by the previously noted author, Pu Songling, complies once again with this trope surrounding an inverted view of reproductive processes performed by men. The scholar of the story, Yang, builds a companionate relationship with a female ghost who dwells in the graveyard next to his lodgings. In the conclusion of the story, the female ghost notifies Yang of her intention to live, "All I need is the essence and blood of a living man and it will be possible to come back to life" (Pu 205). The "essence and blood of a living man" is a material metaphor for a man's reproductive yang essence, semen, and its role in the ghost's rebirth as a human. The scholar Yang takes a blade and slices his arm to drip blood into the ghost's navel. Blood is referenced and believed to be a material contribution from women in reproductive processes, while semen is the male contribution, which initiates a child's growth (Ahern 172). The female ghost instructs that after one hundred days, Yang must exhume her remains from her grave. The imagery of the grave or tomb, which takes the resemblance of a pregnant woman's protruding belly, is intended to represent the ghost as the entity awaiting to be born inside the cavity of the grave. After the ghost's departure, "Over ten days later, Yang fell sick as predicted, and his belly swelled up so painfully he wanted to die" and he excretes a "foul substance" like mud. The time frame of ten days signifies the term of a pregnancy in China, which is the equivalent of about ten months, where pregnancy is counted from the month the mother becomes pregnant to the month the baby is born (Idema 558). Yang's belly swelling and his body leaking mud represents women during the phases of pregnancy and the polluting birth fluids that discharge from the body during this process. When scholar Yang exhumes the ghost's body, he discovers she had been revived by his efforts where "her breath came in and out, finer than a silk thread" ( $\mathrm{Pu}$ 205). Scholar Yang assumes the polluting and burdensome biological processes of a female during pregnancy; however, the ghost's rebirth is still depicted as successful and immaculate because of his biological contribution as a male. Scholar Yang is able to revive the ghost due to the power implied in his material male essence and blood at conception, exemplifying the power underlying his biological reproductive capacity. 


\section{ATTITUDES OF BIOLOGICAL REPRODUCTION EXPRESSED FROM THE PERSPECTIVE OF WOMEN}

Though the selected texts mentioned so far are all fictional and written from the perspective of men, selections from Women's Script are from an autobiographical source written by various women from the nineteenth century. The perspectives expressed in Women's Script continue to maintain and reinforce negative impressions about women's role in reproduction. The selection examined from this text depicts the "sorrows of pregnancy and motherhood," highlighting its hardships and providing warning that "even if [a woman] is fortunate enough to successfully bear her husband a son, her life will still be filled with anxiety and worry" (Idema 557). In "The Ten Months of Pregnancy," one author emphasizes pure suffering during pregnancy and does not mention anything positive about the process. The poem describes the baby as if invoking the image of a parasite: "the embryo has truly installed itself inside you" and "slowly it grows [inside you]" (558). The poem emphasizes pain and burden from pregnancy: "Had I known that being pregnant would be so painful, I would have shaved my head and entered a convent" (558). This expression is intended to amplify the negativity and disdain for the pregnancy experience comparing it to a "debilitating disease." Even when another author depicts herself breastfeeding as part of her relationship with her son, the graphic image is relentlessly negative: "Every drop [of his mother's milk] that he drinks is the blood of his mother, but he keeps on drinking till her body turns all yellow" (561). This conveys the image of her son as a parasite, sucking out her life-force. Women in this passage all describe the burdens during different phases of pregnancy, one woman describing it as "a paper-thin distance from dying" (559). These formulaic and bitter views, from authors in Women's Script who have experienced childbirth and reproductive processes, are consistent with the fictional portrayals which reinforce women's inferior and distasteful biological role in reproduction.

An interpretation and analysis of these pre-modern Chinese texts demonstrates that events like childbirth and other reproductive roles fulfilled by women are framed with anxiety and negativity because they disrupt potential social order. The overarching system of ideas about pollution, that describe women as being internally corrupt and contaminated, is likely the result of this anxiety that resonates with Confucian social mores and reinforces gender hierarchy. These collective attitudes toward reproduction in pre-modern China are deep-rooted and reveal the extensive influence of Confucian gender constructs and social ideals that emphasize social order. The Confucian interpretation of biological processes supports social hierarchies and norms, which influenced a vast array of societal views on human life in pre-modern China. It may be argued that the transition into the socialist era of modern China marked a significant departure from Confucian gender and social hierarchies and their hold on society. However, legacies from these impressions on biological processes in pre-modern China may contribute to modern taboos and superstitions associated with childbirth and menstruation, given the deep-rooted authority and history of Confucian values. Gender 
and social constructs of reproduction in pre-modern Chinese society were created to reinforce social order. Therefore, Confucian social hierarchies and gender constructs underlie the societal views that characterize the female role in reproduction-and signify the female's biological reproductive role as threatening to Confucian social order.

\section{ACKNOWLEDGMENTS}

This paper was developed from the attendance and review of a series of lectures and materials from Sex and Gender in Traditional Chinese Literature course at the University of Oregon. The conductor of these lectures is Associate Professor Maram Epstein, a Ph.D. in Chinese, who inspired the research that formulated this paper. Without the encouragement and guidance of Dr. Epstein, I would not have achieved the clarity and insight on Chinese gender and literary devices needed to accomplish this paper. I would like to include a note of thanks to my humble father, Daniel Arthur Pellouchoud, who has consistently encouraged my pursuit of a higher education degree by motivating and refining my research. Additionally, a thanks to the production team of the undergraduate OURJournal spring edition 2018 at University of Oregon, who promote undergraduate research and processed this paper's publication. I am incredibly grateful for all the acknowledged and unacknowledged forces underlying and driving the thought and production of this paper.

\section{REFERENCES}

Ahern, Emily A. "The Power and Pollution of Chinese Women.” Women in Chinese Society. Edited by M. Wolf and R. Witke, Stanford University Press, 1975, pp. 169-190.

Bray, Francesca. "Reproductive Hierarchies." Technology and Gender: Fabrics of Power in Late Imperial China. Word Press, 1987, pp. 335-368.

Idema, Wilt L.and Beata Grant eds. "The Ten Months of Pregnancy.” The Red Brush: Writing Women of Imperial China. Cambridge, Mass.: Harvard University Asia Center, 2004.

Legge, James. "The Pattern of the Family." The Li Chi: Book of Rites,. University Books, 1967, pp. 449-479.

Liu, Xiang. Exemplary Women of Early China: the Lienü Zhuan of Liu Xiang. Edited and Translated by Anne Behnke. Kinney, Columbia University Press, 2014.

Li, Yu, and Patrick Hanan. "A Male Mencius's Mother Raises Her Son Properly By Moving House Three Times." Silent Operas. Hong Kong: Research Centre for Translation, Chinese University of Hong Kong, 1990, pp. 99-134. 
$\mathrm{Pu}$, Songling, "Liansuo." Translated by Judith Zeitlin. Under Confucian Eyes: Writings on Gender in Chinese History. Edited by Susan Mann and Yu-yin Cheng. Berkeley: University of California, 2001, pp. 199-205.

Pu, Songling. "Painted Skin.” Strange Tales from Make-Do Studio, Beijing: Foreign Languages Press, 1989, pp. 53-60.

Yu Chun-fang translator. "Biography of the Great Compassionate One of Xiangshan by Jiang Zhiqi (1031-1104)." Under Confucian Eyes: Writings on Gender in Chinese History. Edited by Susan Mann and Yu-yin Cheng. Berkeley: University of California, 2001, pp. 31-44. 